Research, part of a Special Feature on Effects of Roads and Traffic on Wildlife Populations and Landscape Function

\title{
Wildlife Tunnel Enhances Population Viability
}

\author{
$\underline{\text { Rodney van der Ree }}^{1}, \underline{\text { Dean Heinze }}^{2}$, Michael McCarthy $^{3}$, and $^{\text {Ian Mansergh }}{ }^{4}$
}

\begin{abstract}
Roads and traffic are pervasive components of landscapes throughout the world: they cause wildlife mortality, disrupt animal movements, and increase the risk of extinction. Expensive engineering solutions, such as overpasses and tunnels, are increasingly being adopted to mitigate these effects. Although some species readily use such structures, their success in preventing population extinction remains unknown. Here, we use population viability modeling to assess the effectiveness of tunnels for the endangered Mountain Pygmy-possum (Burramys parvus) in Australia. The underpasses reduced, but did not completely remove, the negative effects of a road. The expected minimum population size of a "reconnected" population remained $15 \%$ lower than that of a comparable "undivided" population. We propose that the extent to which the risk of extinction decreases should be adopted as a measure of effectiveness of mitigation measures and that the use of population modeling become routine in these evaluations.
\end{abstract}

Key Words: barrier effect; Burramys; population-level impacts; population viability analysis; road ecology; underpass; wildlife crossing structure

\section{INTRODUCTION}

Roads, railways, utility easements, and other linear infrastructure are conspicuous and pervasive components of landscapes throughout the world. The ecological effects of roads and traffic are diverse and may extend hundreds of meters beyond the road (Reijnen et al. 1995, Forman and Deblinger 2000, Eigenbrod et al. 2009). The cumulative effect of the network of roads is potentially large; it has been estimated, for example, that approximately $20 \%$ of the land area of the continental USA is affected by roads and traffic (Forman 2000). Roads and traffic directly and indirectly affect wildlife in a variety of ways (Bennett 1991, Forman et al. 2002) and have contributed to the decline of many wildlife populations.

The barrier or filter effect of roads on wildlife has been the focus of many mitigation efforts, particularly in North America and western Europe (Forman et al. 2002, Irwin et al.2005). The inclusion of wildlife-crossing structures (e.g., overpasses, tunnels, and culverts) in the design and construction of new roads and road upgrades around the world is becoming increasingly common. The effectiveness of wildlife-crossing structures is typically assessed by documenting their rate of use by wildlife, primarily through photographic records, and the detection of footprints in a suitable medium, such as sand or snow (Clevenger and Waltho 2000, Ng et al. 2004, van der Ree et al. 2007). Fewer studies have documented which individuals use the structure (e.g., age and sex parameters), the type of use (e.g., dispersal, migration, or daily foraging), the success of individuals following crossing (e.g., mating) or the reduction in the risk of extinction. These other parameters provide a greater insight into success and allow a more comprehensive assessment of effectiveness.

Use of an under-road tunnel by the mountain pygmy-possum (Burramys parvus) in southeastern Australia led to a demonstrable population-level effect (Mansergh and Scotts 1989). Using trapping and photography, the possum was shown to use the tunnel, and the overwinter survival and sex ratios of the population were "restored." However, despite

\footnotetext{
${ }^{1}$ Australian Research Centre for Urban Ecology, Royal Botanic Gardens Melbourne, ${ }^{2}$ Department of Primary Industries and Water, ${ }^{3}$ Australian Research Centre for Urban Ecology, ${ }^{4}$ Department of Sustainability and Environment
} 
the apparent success of this installation in restoring connectivity and improving survival rates for $B$. parvus, there has been no formal evaluation of the crossing structure on population levels using quantitative modeling.

Population viability analysis is an approach that can be used to evaluate the effectiveness of wildlifecrossing structures by comparing rates of birth, death, and migration before and after the construction of the road and mitigation structure. Excellent long-term data (annual census trapping over a 20-year period) on population parameters for B. parvus exist from populations affected by the road (before and after construction of the tunnel) as well as for a population distant from and unaffected by the road. In this study, we use population viability modeling to predict the likely effect of the road and tunnel on population size and the probability of decline. To our knowledge, this is the first instance where population viability analysis has been used to assess the effectiveness of such mitigation techniques.

Burramys parvus is a small ( $45 \mathrm{~g})$, highly endangered marsupial, endemic to high-altitude boulderfield habitat in southeastern Australia (Mansergh and Scotts 1990, Heinze et al. 2004). Much of its preferred habitat has been cleared, degraded, and fragmented by development associated with alpine ski resorts, and currently $<1600$ females survive in the wild. It is one of Australia's most threatened marsupials. The sexes are usually segregated, except during the mating season (October-December) when males move into the female territory, departing shortly after mating. This lowers the population density and reduces competition for food, allowing females to raise young and increase their body weight before the overwinter hibernation. A major road to the Mount Hotham ski resort obstructed this annual migration at Mount Higginbotham because males avoided crossing the road and the highly disturbed roadside vegetation (Mansergh and Scotts 1989). This resulted in increased population densities and altered sex ratios in the female-dominated area, and reduced overwinter survival. In 1985, two rocklined tunnels were built under the road and an abutting $60 \mathrm{~m}$ of boulderfield corridor to mitigate this problem (Mansergh and Scotts 1989). The tunnels were concrete box culverts $(0.9 \times 1.2 \mathrm{~m})$, approximately $16 \mathrm{~m}$ in length, traversing approximately $7 \mathrm{~m}$ of road and $9 \mathrm{~m}$ of cleared verge. Traffic volume along the road in autumn (April)
2001 was 400 vehicles per day (VicRoads, unpublished data). Winter estimates of traffic volume are unavailable due to logistical difficulties of using counters in the snow, but would have been significantly higher. However, winter traffic volume is somewhat irrelevant because the possums hibernate during winter. The site was important because it was central to the habitat that supported $>50 \%$ of the world population of the species.

\section{METHODS}

The size and distribution of populations of $B$. parvus at Mount Higginbotham have been assessed annually since 1983 (Mansergh 1984). A capturemark-release program was conducted over a series of trapping grids. Biological data were collected and animals fitted with ear tags. Here, we use a subset of the census data set (1982/83-2002/03) including one population that has been divided by the road for $>25$ years, for which data were collected before (1983-1985) and after (1986-2003) mitigation; and a second population unaffected by the road, approximately $0.5 \mathrm{~km}$ distant from the "road" population. Both populations experience similar climatic and environmental conditions, however, are separated by at least two ski runs, each 20-30 $\mathrm{m}$, effectively isolating both populations from each other. Despite being physically capable of moving this distance, no individuals have been detected moving between the two populations.

The population was modeled using a Ricker (1975) function with an additional term to account for effects of changes in sex ratio. Thus, the expected logarithmic growth rate was

$\ln \left[N_{t+1} / N_{t}\right]=a+b \times N_{t}+s \times S_{t}+\operatorname{norm}(0, \sigma)$,

where $N_{t}$ is the population size (number of females) at time $t, S_{t}$ is the sex ratio (ratio of females to males), $\operatorname{norm}(0, \sigma)$ is a normal random deviate with mean zero and standard deviation $\sigma$, and $a, b$, and $s$ are parameters influencing the maximum population growth rate, and the rate at which this growth rate declines with increasing population density and sex ratio. The normal random deviate was included to model environmental stochasticity. The sex ratio was the observed ratio of females and males that were captured. This model is a simplified version of that developed by McCarthy and Broome (2000) for B. parvus in New South Wales, Australia. The simplified version was used because age-structure 
data were unavailable, but it still provided similar predictions to the original model. Demographic stochasticity was modeled by drawing the population size from a Poisson distribution (Akçakaya 1991). Simulations were run for 20 years with 10000 iterations of the model.

We modeled only linear changes in the logarithmic population growth rate with changes in the sex ratio. Sex ratio is used as a surrogate measure for the impacts of the road on dispersal ability. As population size declines, it is conceivable that the number of males will become limiting. However, $B$. parvus is polygynous, and the number of males is unlikely to be limiting except at very small population sizes. In the data and the model simulations, the population sizes of females were well above zero and a quadratic relationship for sex ratio did not improve the fit, so it was assumed that the linear form sufficed.

Parameter estimates for the model (Table 1) were obtained using Bayesian Markov chain Monte Carlo (MCMC) methods in WinBUGS (Spiegelhalter et al. 2003). A Bayesian approach was used because it provided a convenient method for accounting for uncertainty in the estimates of population size (measured by the standard error of the population estimate obtained from mark-recapture analysis), and for propagating uncertainty about parameter estimates through to predictions. Vague priors were used for the parameter estimates to reflect a lack of other useful information about the population dynamics of the species. Posterior distributions were obtained from 100000 MCMC samples, after discarding the first 5000 samples as a burn-in. The code used in the WinBUGS analysis is given in Appendix 1.

The predicted effect of the tunnel in mitigating the impact of the road was assessed by substituting the average pre-tunnel sex ratio, post-tunnel sex ratio, and the sex ratio in the unaffected population into the model of predicted growth rate $(9.5,4.1$, and 2.4 , respectively). The sex ratio of the three populations was the primary input into the model because it best summarized the effect of the road on movement patterns and overwinter survival. Thus, the model predicts risk for a site affected by a road without mitigation, a road with mitigation, and a site without a road, assuming an equilibrium population size in the absence of the road of 82 females. This number was also used as the initial population size. The median population size over the 20 -year period was predicted using the best parameter estimates (means of the posterior distributions of the parameter estimates). Additionally, the effect of parameter uncertainty was investigated by examining the posterior distribution of the expected minimum population size (EMP) over the 20-year period. The EMP is the smallest population size expected within a given time frame and summarizes the risk of decline (McCarthy and Thompson 2001). See McCarthy (2007) for the method for calculating EMP within WinBUGS.

\section{RESULTS}

Summary statistics of the posterior distribution of the model parameters indicate that population growth rates decline with increasing population size and sex ratio because the parameters $b$ and $s$ are both negative (Table 1).

Our model of the effectiveness of a tunnel for $B$. parvus predicted that the median population size at the unmitigated road was $40 \%$ lower than at a site without a road (median population size at site without road was about 80 , 95\% CI 48-125, compared with about $53,95 \%$ CI 35-86 at the site with a road and tunnel) (Fig. 1). The probability of extinction (zero population size) within 20 years was predicted to be zero in all scenarios considered. We have used the word predicted because we have had to predict what the situation might be at a road that was unmitigated. The tunnel reduced the barrier effect of the road and adjacent disturbance, but there remained a $15 \%$ reduction in the median population size of females (Fig. 1). The influence on the EMP of females showed a similar pattern (Fig. 2), with the unmitigated road resulting in the fewest females after 20 years. Uncertainty in the parameter estimates of the population model led to uncertainty in the predictions, with the $95 \%$ credible intervals for the EMP being relatively wide (Fig. 2). The difference between the EMP in the absence of the road and a site with an unmitigated road is large (mean difference of 17 females with $95 \%$ credible interval of 1.5-35). In contrast, the difference between the predictions without a road and a mitigated road were relatively small (mean difference of 3.5 females with $95 \%$ credible interval of 0.5-8). These credible intervals are for the difference in EMP between two scenarios, which is different from the credible intervals in Fig. 2 that represent uncertainty in the EMP of individual scenarios. 
Table 1. Mean, standard deviation (s.d.) and 95\% credible interval for the posterior distributions of the parameters of the population model.

\begin{tabular}{llll}
\hline \hline Parameter & mean & s.d. & $95 \%$ credible interval \\
\hline$a$ & 1.3 & 0.32 & $(0.62,1.9)$ \\
$b$ & -0.014 & 0.0035 & $(-0.0069,-0.021)$ \\
$s$ & -0.054 & 0.025 & $(-0.0086,-0.10)$ \\
$\sigma$ & 0.21 & 0.065 & $(0.093,0.35)$ \\
\hline
\end{tabular}

\section{DISCUSSION}

The original study on the effectiveness of the mitigation works for $B$. parvus (Mansergh and Scotts 1989) concluded that the tunnels and rocklined corridor restored habitat continuity and population processes. Our simulation supports this assertion, and quantified the extent to which the tunnels mitigated the barrier effect of the road. Quantifying success in this way is a first because other evaluations typically assume success after recording the presence of animals using the underpass or overpass by footprint or camera. Our model suggests that although the tunnels did restore population processes for $B$. parvus, they did not completely eliminate the effects of the road. Even after mitigation, the median population size of females was predicted to be $15 \%$ lower than if the road had not been constructed. This reduction may be due to an insufficient number of tunnels, mortality due to collision with vehicles or natural variation in population size. The issue of even relatively small reductions in population size may not be trivial to population survival, especially for rare or uncommon species. For example, a genetically isolated population of approximately 350 individuals of $B$. parvus at Mount Buller declined by $90 \%$ in the 10 years to 2006 due to habitat destruction and fragmentation that compounded predation and restricted animal movement (Heinze 2006). If population modeling had been used at the impact-assessment stage, the population decline might have been avoidable. Subsequently, modeling has been used to evaluate the costs and benefits of proposed recovery actions for this Mount Buller population, resulting in an integrated predator-control program, extensive habitat restoration works, and the removal of wild animals for a captive breeding program.

Our modeling of the effects of the road and tunnels on $B$. parvus demonstrates one approach that explicitly and quantitatively incorporates population viability into the assessment of mitigation effectiveness. The broad aim of most mitigation projects is to "increase the permeability of a road corridor" (Forman et al. 2002: 161). According to this criterion, most overpasses and underpasses would be considered successful (see van der Ree et al. 2007). Interestingly, there is even a lack of evidence to assess whether wildlife overpasses and underpasses are able to effectively facilitate gene flow across potential barriers (Corlatti et al. 2009). However, we propose that a fundamental measure of the effectiveness of wildlife-crossing structures should also include the extent to which they increase the viability of local populations. This must be considered a key measure of success because the passage of animals under or over a road may not be sufficient to counteract the numerous deleterious effects of the road along its entire length (e.g., see Jaeger et al. 2005). Population modeling (using a range of different modeling methods) can be used before construction to evaluate the relative benefits of different mitigation options, as well as to evaluate effectiveness after completion. The greatest risk from a conservation perspective is that insufficient or poorly designed wildlife-crossing structures be installed while adjacent populations continue to decline in size.

We are not advocating that our specific modeling approach is the only way to evaluate effectiveness, as there are a range of different modeling 
Fig. 1. Predicted population size of female B. parvus at Mount Higginbotham for 20 years in the presence of the road (A), after construction of tunnels to mitigate the barrier effect of a road (B), and in the absence of the road (C). The predictions are based on mean parameter estimates and show the median population size and the $95 \%$ prediction interval based on environmental and demographic stochasticity.
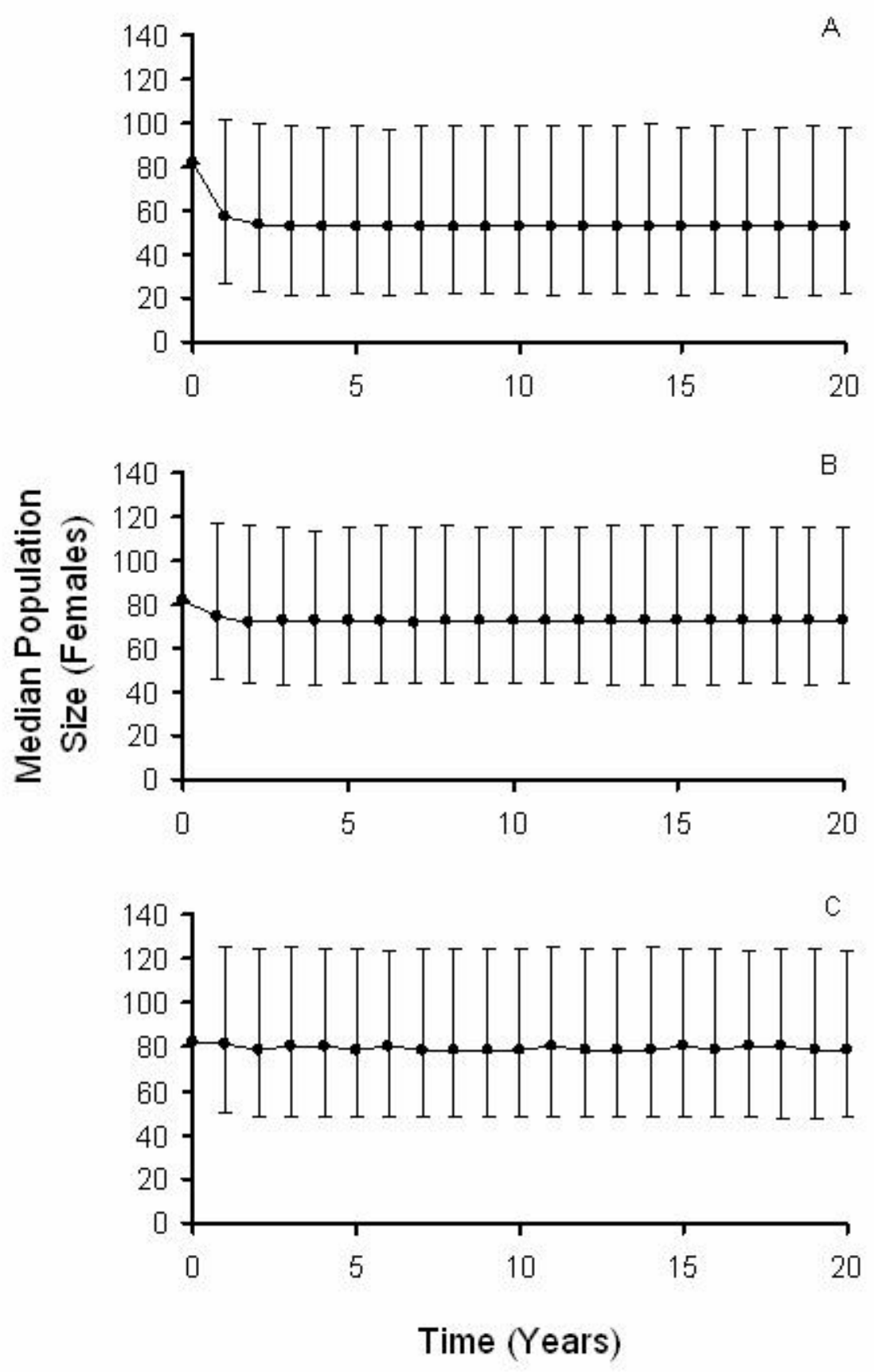
Fig. 2. Expected minimum female population size of B. parvus at Mount Higginbotham, 20 years after construction of tunnels and boulder corridor to mitigate the barrier effect of a road and adjacent habitat degradation. The error bars are $95 \%$ credible intervals that propagate the uncertainties in parameter estimates.

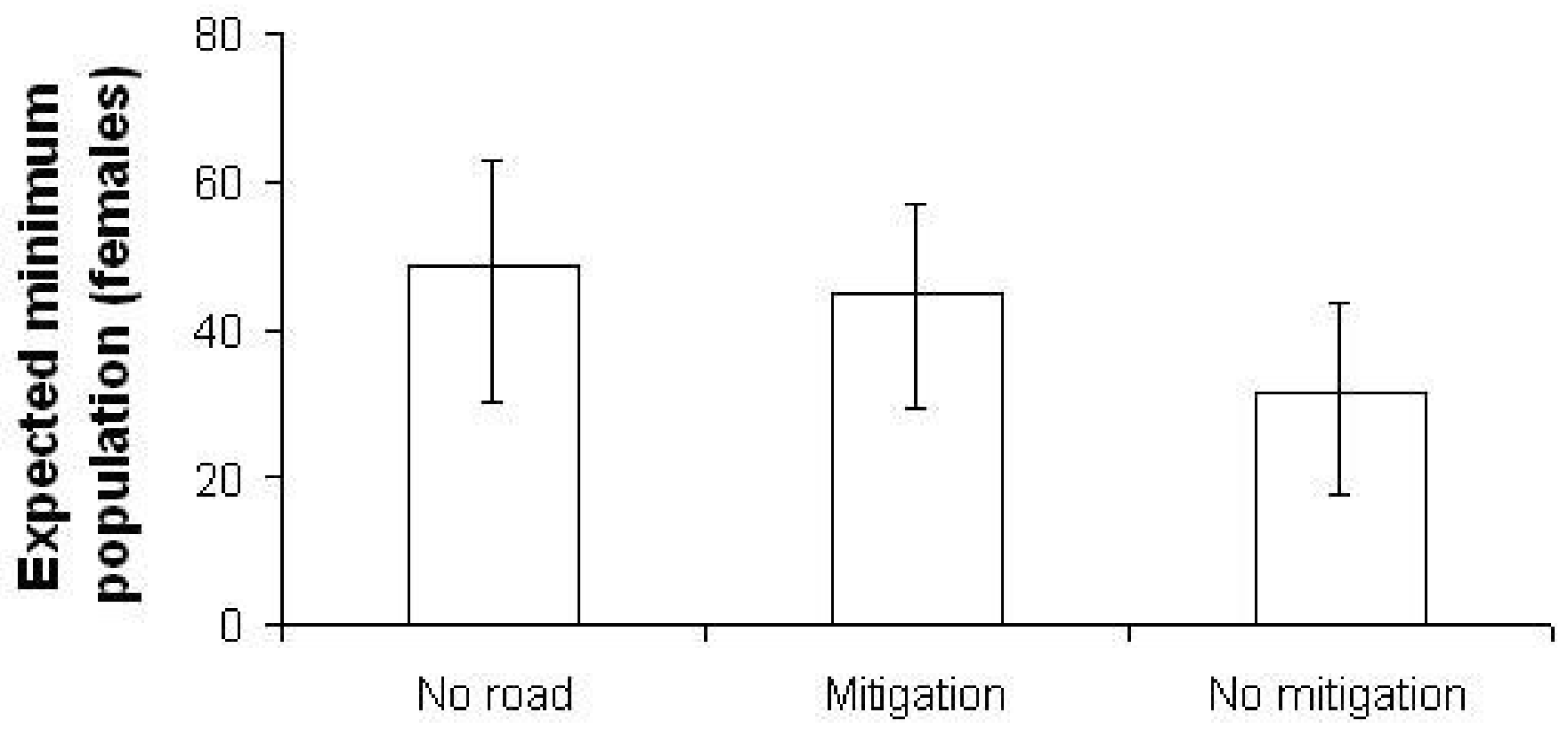

\section{Treatment}

approaches available. The critical issue is that the effectiveness (and not just usage) of wildlifecrossing structures needs to be evaluated, and that population modeling provides a tool to achieve this. We were fortunate to have a 20 -year data set with which to parameterize our model, and in most cases, such detailed information does not exist. However, parameters for our model are based on data collected after the road and mitigation measures were implemented. Nevertheless, a range of different model types are available that can incorporate a differing array of biological, ecological, and landscape information to evaluate effectiveness at reducing the risk of extinction, with each suited to different situations or conditions. For example, the spatially explicit population models used to quantify the effects of roads on the dispersal of the Eurasian lynx (Lynx lynx) in Germany (KramerSchadt et al. 2004) could be adapted to also evaluate the effectiveness of mitigation works. Optimal locations for crossing structures and crossing rates that are likely to be required to achieve desired population-level outcomes could be predicted using spatially explicit models of population dynamics (see van der Grift and Pouwels 2006). This will also permit an evaluation of cost effectiveness of different mitigation options. For example, sufficient rates of crossing under particular conditions might be achieved with three culverts, which may be cheaper to install than a single land bridge. Alternatively, modeling may predict that the only option to maintain a certain-sized population (and hence reduce the risk of extinction to an acceptable level) is to move or close the road and not fragment the habitat.

Evaluating the effectiveness of wildlife-crossing structures by measuring the rate of use by individuals is a first step to a comprehensive analysis of success. The risk in not evaluating effectiveness at the population level is that mitigation measures may only partially decrease the 
barrier effect, without a satisfactory increase in population viability. It is imperative that mitigation measures increase population viability, given the large amounts of money required to install and maintain them. Road construction and management agencies may face legislative requirements to ensure that their actions do not further endanger species that are facing extinction. Finally, it is pertinent to remember that the barrier effect is just one of the potential impacts of roads on fauna, and mitigation that addresses this may only increase viability within the limits posed by other effects.

Responses to this article can be read online at:

http://www.ecologyandsociety.org/voll4/iss2/art7/responses/

\section{Acknowledgments:}

This research was supported by funding from the Australian Research Council, the Department of Sustainability and Environment, the Baker Foundation, and VicRoads. Kirsten Parris and Andrew Bennett commented on the manuscript. All work involving animals was conducted according to the guidelines of the Animal Ethics Committees of LaTrobe University and the Department of Sustainability and Environment.

\section{LITERATURE CITED}

Akçakaya, H. R. 1991. A method for simulating demographic stochasticity. Ecological Modelling 54:133-136.

Bennett, A. F. 1991. Roads, roadsides and wildlife conservation: a review. Pages 99-118 in D. A. Saunders and R. J. Hobbs, editors. Nature conservation 2: the role of corridors. Surrey Beatty and Sons, Chipping Norton, New South Wales, Australia.

Clevenger, A. P., and N. Waltho. 2000. Factors influencing the effectiveness of wildlife underpasses in Banff National Park, Alberta, Canada. Conservation Biology 14:47-56.

Corlatti, L., K. Hacklander, and F. Frey-Roos. 2009. Ability of wildlife overpasses to provide connectivity and prevent genetic isolation.
Conservation Biology, in press. DOI: 10.1111/ j.1523-1739.2008.01162.x.

Eigenbrod, F., S. Hecnar, and L. Fahrig. 2009. Quantifying the road-effect zone: threshold effects of a motorway on anuran populations in Ontario, Canada. Ecology And Society, in press.

Forman, R.T.T.2000. Estimate of the area affected ecologically by the road system in the United States. Conservation Biology 14:31-35.

Forman, R. T. T., and R. D. Deblinger. 2000. The ecological road-effect zone of a Massachusetts (USA) suburban highway. Conservation Biology 14:36-46.

Forman, R. T. T., D. Sperling, J. A. Bissonette, A. P. Clevenger, C. D. Cutshall, V. H. Dale, L. Fahrig, R. France, C. R. Goldman, K. Heanue, J. A. Jones, F. J. Swanson, T. Turrentine, and T. C. Winter. 2002. Road ecology. Science and solutions. Island Press, Washington, D.C., USA.

Heinze, D. 2006. Monitoring of the mountain pygmy-possum population within the Mount Buller Alpine Resort, November 2005 and JanuaryFebruary 2006. Consultants report to the Mount Buller and Mount Stirling Resort Management Board.

Heinze, D., L. S. Broome, and I. M. Mansergh. 2004. A review of the ecology and conservation of the mountain pygmy-possum Burramys parvus. Pages 254-267 in R. Goldingay and S. Jackson, editors. The biology of Australian possums and gliding possums. Surrey Beatty and Sons, Chipping Norton, Australia.

Irwin, C. L., P. Garrett, and K. P. McDermott. 2005. Proceedings of the 2005 International Conference on Ecology and Transportation. Center for Transportation and Environment, North Carolina State University, Raleigh, North Carolina, USA.

Jaeger, J. A. G., J. Bowman, J. Brennan, L. Fahrig, D. Bert, J. Bouchard, N. Charbonneau, K. Frank, B. Gruber, and K. T. von Toschanowitz. 2005. Predicting when animal populations are at risk from roads: an interactive model of road avoidance behavior. Ecological Modelling 185:329-348. 
Kramer-Schadt, S., E. Revilla, T. Wiegand, and U. Breitenmoser. 2004. Fragmented landscapes, road mortality and patch connectivity: modelling influences on the dispersal of Eurasian lynx. Journal of Applied Ecology 41:711-723.

Mansergh, I. M. 1984. Ecological studies and conservation of Burramys parvus. Pages 545-552 in A. P. Smith and I. D. Hume, editors. Possums and gliders. Australian Mammal Society, Sydney, Australia.

Mansergh, I. M., and D. J. Scotts. 1989. Habitat continuity and social organisation of the mountain pygmy-possum restored by tunnel. Journal of Wildlife Management 53:701-707.

Mansergh, I. M., and D. J. Scotts. 1990. Aspects of the life history and breeding biology of the mountain pygmy-possum, Burramys parvus (Marsupialia: Burramyidae) in alpine Victoria. Australian Mammalogy 13:179-191.

McCarthy, M. A. 2007. Bayesian methods for ecology. Cambridge University Press, Cambridge, UK.

McCarthy, M. A., and L. S. Broome. 2000. A method for validating stochastic models of population viability: a case study of the mountain pygmy-possum (Burramys parvus). Journal of Animal Ecology 69, 599-607.

McCarthy, M. A., and C. Thompson. 2001. Expected minimum population size as a measure of threat. Animal Conservation 4:351-355.

Ng, S. J., J. W. Dole, R. M. Sauvajot, S. P. D. Riley, and T. J. Valone. 2004. Use of highway undercrossings by wildlife in southern California. Biological Conservation 115:499-507.

Reijnen, R., R. Foppen, C. Terbraak, and J. Thissen. 1995. The effects of car traffic on breeding bird populations in woodland. III. Reduction of density in relation to the proximity of main roads. Journal of Applied Ecology 32:187-202.

Ricker, W. E. 1975. Computation and interpretation of biological statistics of fish populations. Fisheries Research Board of Canada, Ottawa, Ontario, Canada.
Spiegelhalter, D., A. Thomas, N. Best, and D. Lunn. 2003. WinBUGS User Manual Version 1.4. MRC Biostatistics Unit, Cambridge, UK.

van der Grift, E. A., and R. Pouwels. 2006. Restoring habitat connectivity across transport corridors: identifying high-priority locations for defragmentation with the use of an expert-based model. Pages 205-231 in J. Davenport and J. L. Davenport, editors. The ecology of transportation: managing mobility for the environment Springer, Dordrecht, The Netherlands.

van der Ree, R., E. A. van der Grift, C. Mata, and F. Suarez. 2007. Overcoming the barrier effect of roads-how effective are mitigation strategies? An international review of the effectiveness of underpasses and overpasses designed to increase the permeability of roads for wildlife. Pages 423-431 in C. L. Irwin, D. Nelson, and K. P. McDermott, editors. International Conference on Ecology and Transportation Center for Transportation and The Environment, North Carolina State University, Raleigh, North Carolina and Little Rock, Arkansas, USA. 
APPENDIX 1. Supporting online material (code for population model for WinBugs)

Appendix 1. Code for population model for WinBugs. The data used to model the effectiveness of tunnels for Burramys parvus are available from Dean Heinze upon request.

model

\{

$\operatorname{tau}[1]<-1 /(\mathrm{SE}[1] * \mathrm{SE}[1])$

\# precision of the estimate in year 1

$\#$ precision $=1 /$ variance

$\mathrm{A}[1] \sim \operatorname{dnorm}(\mathrm{F}[1], \operatorname{tau}[1]) \#$ initial population size

for (i in 2:22) \# for each subsequent year

\{

$\mathrm{F}[\mathrm{i}] \sim \operatorname{dnorm}(\mathrm{A}[\mathrm{i}], \operatorname{tau}[\mathrm{i}])$

\# estimate population size deviates from actual

$\operatorname{tau}[\mathrm{i}]<-1 /(\mathrm{SE}[\mathrm{i}] * \mathrm{SE}[\mathrm{i}])$

\# precision of estimate

$\mathrm{A}[\mathrm{i}] \sim \operatorname{dpois}(\operatorname{pred}[\mathrm{i}])$

\# actual population size drawn from Poisson

$\operatorname{pred}[\mathrm{i}]<-\mathrm{A}[\mathrm{i}-1] * \exp \left(\mathrm{a}+\mathrm{bF}^{*} \mathrm{~A}[\mathrm{i}-1]+\mathrm{bS} * \mathrm{SR}[\mathrm{i}-1]+\operatorname{ann}[\mathrm{i}]\right)$ \# Ricker model

$\operatorname{ann}[\mathrm{i}] \sim \operatorname{dnorm}(0, \mathrm{t})$

\# normal deviate representing environmental variation

\}

ev $<-1 / \operatorname{sqrt}(\mathrm{t})$

\# standard deviation for environmental variation

\# vague priors

$\mathrm{t} \sim \operatorname{dgamma}(0.001,0.001)$ \# precision of env. variation

$\mathrm{a} \sim \operatorname{dnorm}(0,1.0 \mathrm{E}-6)$ \# intercept of Ricker model

$\mathrm{bF} \sim \operatorname{dnorm}(0,1.0 \mathrm{E}-6)$ \# effect of density dependence

$\mathrm{bS} \sim \operatorname{dunif}(0,1) \#$ effect of sex ratio

\}

ADD DATA HERE

END 